\title{
The Effect of Low Level Laser Therapy on Direct Pulp Capping in Dogs
}

\author{
Maryam Bidar ${ }^{1}$, Siavash Moushekhiann ${ }^{1}$, Maryam Gharechahi ${ }^{2 *}$, Ali Talati ${ }^{1}$, Farzaneh Ahrari ${ }^{3}$, Maryam \\ Bojarpour ${ }^{4}$
}

'Dental Research Center, Department of Endodontics, School of Dentistry, Mashhad University of Medical Sciences, Mashhad, Iran

${ }^{2}$ Dental Materials Research Center, Department of Endodontics, School of Dentistry, Mashhad University of Medical Sciences, Mashhad, Iran

${ }^{3}$ Laser Research Center, Department of Orthodonthics, School of Dentistry, Mashhad University of Medical Sciences, Mashhad, Iran

${ }^{4}$ Dentist

\author{
*Correspondence to \\ Maryam Gharechahi, DDS. \\ Department of Endodontics, Faculty \\ of Dentistry, Vakilabad Blvd, \\ Mashhad. \\ P.O. Box: 91735-984, Iran \\ Tel: +98-9155140340; \\ Fax: +98-0513-8829500 \\ Email: gharechahim@mums.ac.ir
}

Published online 18 July 2016

\begin{abstract}
Introduction: The aim of this study was to determine the histologic effect of low level laser therapy (LLLT) with or without the use of mineral trioxide aggregate (MTA) on exposed pulp tissues of dogs.

Methods: Twenty-five premolar teeth in three healthy mature dogs were randomly divided into five groups. In group 1, the pulp tissue was capped with MTA. In groups 2 and 3, before capping with MTA, the exposure site was irradiated by low power lasers at 630 $\mathrm{nm}\left(20 \mathrm{~mW}, 150\right.$ seconds, $\left.7.5 \mathrm{~J} / \mathrm{cm}^{2}\right)$ and $810 \mathrm{~nm}$ (peak power $80 \mathrm{~W}$, average power 50 $\mathrm{mW}, 1500 \mathrm{~Hz}, 50$ seconds, $6.25 \mathrm{~J} / \mathrm{cm}^{2}$ ) wavelengths, respectively. In groups 4 and 5, the exposure site was irradiated similar to that described in groups 2 and 3, but the pulp tissue was covered by gold foil instead of MTA. After 2 months, the animals were sacrificed and the samples were prepared for histologic evaluation.

Results: There were differences in pulpal response and dentinal barrier formation among the study groups. The morphology of pulpal tissue and the integrity of dentinal barrier and formation of odontoblastic layer were more favorable in the first three groups. The occurrence of extensive and intense inflammation and necrosis was more frequent in groups 4 and 5 .

Conclusion: Under the conditions used in this study, the presence of MTA as a pulp capping material was more important than laser therapy in the success of direct pulp capping (DPC) treatment. MTA proved to be an effective material either alone or in combination with laser irradiation in vital pulp therapy.

Keywords: low level laser therapy; vital pulp therapy; dentinal bridge; gold foil; mta; pulp capping; pulp morphology
\end{abstract}

\section{Introduction}

Dental pulp is a unique soft tissue containing blood vessels, nerve fibers, collagen fibers, fibroblasts, odontoblasts, and immune cells. Like other connective tissues, dental pulp has the capacity of healing against external stimuli. ${ }^{1}$ Direct pulp capping (DPC) is one of the vital pulp therapy modalities, attempting to maintain the integrity of pulpal tissue. In this technique, a biocompatible material is placed on the pulp exposed by caries or trauma in order to protect the pulpal tissue from bacterial microleakage. ${ }^{2}$ This can promote dentinal bridge formation and lead to maintenance of pulp vitality. It is believed that an important marker of pulpal wound repair is dentinal bridge formation. ${ }^{1}$ The presence of reparative dentin is a barrier against the penetration of external stimuli, there- fore, the amount and homogeneity, and the presence or absence of dentinal tubules within reparative dentin are important factors in the success of DPC treatment.

Historically, DPC was introduced by Philip Pfaff in 1765 by using a gold foil. ${ }^{3}$ From that time, various materials have been used for DPC including glass ionomers, adhesive resins, zinc oxide eugenol (ZOE) and calcium hydroxide $\left[\mathrm{Ca}(\mathrm{OH})_{2}\right]$. The use of these materials is associated with some disadvantages, such as microleakage, and some physical or chemical problems that may lead to pulp injuries before complete dentinal bridge formation, hence these materials are not commonly used today for DPC. ${ }^{4}$ In 1995, the mineral trioxide aggregate (MTA) was introduced by Torabinejad as a retrofill material in endodontic treatments. The excellent properties of MTA 
including high biocompatibility, good marginal seal, alkaline $\mathrm{pH}$, slow release of $\mathrm{Ca}^{2+}$, and stimulation of cytokine release made this material as a suitable substance for DPC. It has been demonstrated that the use of MTA can lead to an increased rate of cell proliferation and the induction of homogenous calcified bridge underneath the exposed pulp tissue. ${ }^{1}$

Low level laser therapy (LLLT) has been extensively used in medicine and dentistry due to its anti-inflammatory, analgesic and biostimulative effects and its great benefits in accelerating the wound healing process. ${ }^{5-10}$ These excellent properties suggest that LLLT could play a great role in the success of DPC treatment by promoting hard tissue formation and accelerating the inflammatory process in damaged pulp tissues. Although some recent studies investigated the clinical, radiographic and histopathologic outcomes of LLLT in pulpotomy of primary teeth, ${ }^{11-13}$ but there are few studies regarding the effect of LLLT on DPC, ${ }^{14}$ and there has not been any comparison done between the effectiveness of low power red and infrared lasers in DPC. Furthermore, the quality of reparative dentin formed following laser treatment of exposed pulpal tissue has not been evaluated in previous investigations. Therefore, this study was conducted to determine the histologic effect of irradiation from low power red and infrared lasers with or without using MTA on exposed pulp tissues of dogs.

\section{Methods}

The study consisted of 25 maxillary and mandibular premolar teeth in three healthy mature dogs (Iranian mix, $15-30 \mathrm{~kg}$ weight) with mean age of 2 years 2 months old. The study protocol was approved by the ethics committee of Mashhad University of Medical Sciences (the approval code: 89309). Before performing the experiment, the periodontal condition of premolar teeth was assessed with a periodontal probe and the health of the pulp and periapical tissues was evaluated by periapical radiographs. The teeth that had caries and periodontal or periapical problems were excluded from the sample.

Acepromazine, diazepam, and ketamine were used for general anesthesia. The teeth were locally anesthetized by injection of $2 \%$ lidocaine combined with 1:100000 epinephrine (Darou Pakhsh, Iran) and then were isolated with a rubber dam (Supa, Iran) (Figure 1). A 0.2\% chlorhexidine mouthrinse (Hexodine, World Health Laboratories Co., Tehran, Iran) was used for the disinfection of teeth and rubber dam. The pulpal tissue of each tooth was exposed by a round bur (Dia Dent Co., Seoul, Korea,) with a terminal diameter of $1.5 \mathrm{~mm}$. The dentinal chips were removed by normal saline irrigation. Pulp bleeding was controlled by a slight pressure from some cotton pieces wetted by hypochlorite sodium (Razi Serum, Iran). The teeth in the study groups underwent DPC by one of the following methods:

Group 1: The teeth were capped by MTA (Proroot, Dentsply, Tusla, USA).

Group 2: The exposed pulp areas in this group were irra- diated by a low level red laser (LLRL) (Mustang 2000+, Moscow, Russia), emitting a wavelength of $630 \mathrm{~nm}$. The laser was operated in continuous wave mode at a power of $20 \mathrm{~mW}$ and was held manually at an approximate distance of $2 \mathrm{~mm}$ from the exposure site. The beam was delivered through a nozzle, which was held manually at an approximate distance of $2 \mathrm{~mm}$ from the target area. The duration of irradiation was 150 seconds and the spot size was approximately $0.2 \mathrm{~cm}^{2}$. Considering the $50 \%$ energy loss through the nozzle, the effective energy delivered to the tissue was estimated to be $1.5 \mathrm{~J}$ and the energy density was calculated to be $7.5 \mathrm{~J} / \mathrm{cm}^{2}$. Following laser therapy, the teeth were capped by MTA.

Group 3: The teeth in this group were irradiated with a low level infrared laser (LLIL; wavelength $810 \mathrm{~nm}$; Mustang 2000+, Moscow, Russia). The laser was applied with a peak power of $80 \mathrm{~W}$, average power of $50 \mathrm{~mW}$ and frequency of $1500 \mathrm{~Hz}$, pulse length of $1 \mu \mathrm{s}$, and spot size of $0.2 \mathrm{~cm}^{2}$ for 50 seconds per tooth. The beam was delivered through a nozzle which was held manually at an approximate distance of $2 \mathrm{~mm}$ from the target area. Considering the $50 \%$ energy loss through the nozzle, the effective energy delivered to the tissue was estimated to be $1.25 \mathrm{~J}$ and the energy density was calculated to be $6.25 \mathrm{~J} / \mathrm{cm}^{2}$. The teeth were then capped by MTA.

Group 4: The low power red laser was irradiated to the exposed pulp tissue similar to that described in group 2 . However, instead of MTA, a gold foil was used for capping the exposure site.

Group 5: A low power infrared laser was employed to irradiate the exposed pulp tissue similar to that described in group 3, but a gold foil was used, instead of MTA, for capping the exposure area.

In all groups, the cavities were filled with glass ionomer cement (GC Industrial Co., Tokyo, Japan). After 8 weeks, the dogs were sacrificed and a vital perfusion was accomplished. The teeth and surrounding tissues were block sectioned and immersed in $10 \%$ formalin. Then the tissues were decalcified with $17 \%$ EDTA over a period of 6 months and embedded in paraffin. After serial sectioning of the samples in 4-6 $\mu \mathrm{m}$ thickness, the specimens were stained with hematoxylin and eosin ( $\mathrm{H} \& \mathrm{E})$. The specimens were then coded and evaluated by a blind investiga-

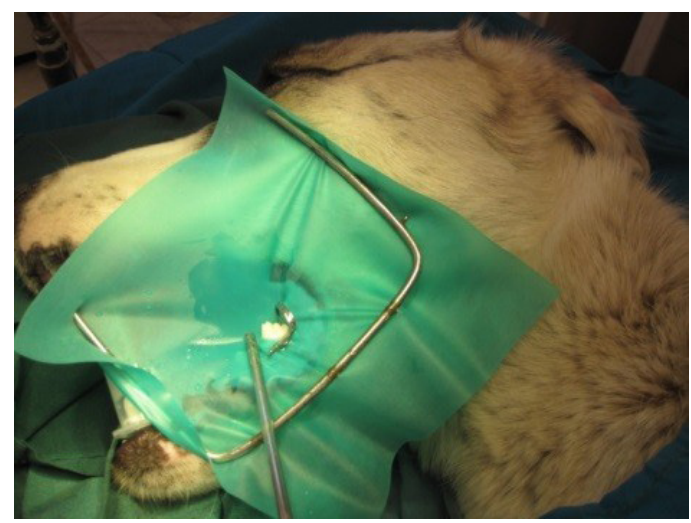

Figure 1. The teeth were isolated with a rubber dam. 
tor under an optical microscope at $40 \times$ and $100 \times$ magnifications. The histopathological assessment performed in this study consisted of 3 parts and each part was classified as described below. ${ }^{15}$

Part 1. Inflammatory Reaction, Including Type, Intensity and Extension

\section{(a) Type}

Grade 1: acute and chronic inflammation; Grade 2: chronic inflammation; Grade 3: without inflammation.

(b) Intensity

Grade 1: severe inflammation (more than 60 inflammatory cells) or abscess formation; Grade 2: mild (0-30 inflammatory cells) to moderate (30-60 inflammatory cells) inflammation; Grade 3: without inflammation.

\section{(c) Extension}

Grade 1: entire coronal pulp; Grade 2: under the exposure area; Grade 3: without inflammation.

Part 2. Hard Tissue Formation Including Continuity, Morphology, and Thickness

(a) Continuity

Grade 1: absence of hard tissue formation; Grade 2: moderate contact of capping material with the dental pulp; Grade 3: complete bridge formation.

(b) Morphology

Grade 1: without dentinal tubules; Grade 2: irregular tubular dentin; Grade 3: regular tubular dentin.

(c) Thickness

Grade 1: less than $100 \mu \mathrm{m}$; Grade 2: 100-250 $\mu \mathrm{m}$; Grade 3: more than $250 \mu \mathrm{m}$.

Part 3. Histopathological Changes in Soft Tissue Including Necrosis, Odontoblastic Layer Formation and Calcification

\section{(a) Necrosis}

Grade 1: complete necrosis; Grade 2: partial necrosis; Grade 3: without necrosis.

(b) Odontoblastic Layer Formation

Grade 1: absence of odontoblastic layer; Grade 2: presence of odontoblastic layer; Grade 3: parallel pattern of cells (palisade form).

(c) Calcification

Grade 1: diffuse calcification; Grade 2: pulp stone; Grade 3: without calcification.

\section{Results}

The outcome of histological assessment is explained separately regarding the inflammatory reaction, hard tissue formation, and histopathological changes in soft tissue in the following:

\section{Inflammatory Reaction}

No inflammatory reaction was observed in group 3 (LLIL+MTA), but chronic inflammation (grade 2) with mild to moderate intensity (grade 2) was observed in $20 \%$ of the specimens in groups 1 and 2, 60\% of the specimens in group 4 and $40 \%$ of the specimens in group 5 under the exposure site (Figure 2). Furthermore, acute and chronic inflammation (grade 1) with mild to moderate intensity (grade 2) was observed in $20 \%$ of the specimens in group 5 under the exposed tissue. The remaining specimens in the study groups had no sign of inflammation (Table 1).

\section{Hard Tissue Formation}

A dentinal bridge was formed in $100 \%$ of the specimens in groups 1 to 3 and $80 \%$ of the specimens in groups 4 and 5 (Figure 3 ). In groups 1 to 3 , the continuity of the dentinal bridge was mainly classified as grade 3 (complete bridge formation), whereas in groups 4 and 5, moderate contact of capping material with the dental pulp (grade 2) was more frequent. In groups 1 to 3 , the dentinal bridge thickness was mainly in the range of 100-250 $\mu \mathrm{m}$ (grade 2) or more than $250 \mu \mathrm{m}$ (grade 3), whereas groups 4 and 5 frequently showed dentinal bridge with less than $250 \mu \mathrm{m}$ thickness (grades 1 and 2). Regarding dentin morphology, most of the specimens in the study groups exhibited irregular tubular structure (grade 2). Only $20 \%$ of the specimens in groups $1,3,4$, and 5 showed regular tubular dentin (grade 3 ) and $20 \%$ of the specimens in groups 4 and 5 indicated atubular structures (grade 1) (Table 2).

\section{Histopathologic Changes in Soft Tissue}

None of the specimens in groups 1 to 3 showed pulp necrosis, whereas partial pulp necrosis was observed in $20 \%$ of the specimen in groups 4 and 5 (Figure 4). An odontoblastic layer was formed adjacent to the dentinal bridge in $100 \%$ of the specimens in groups 1 to 3 . Twenty percent of the specimens in groups 4 and 5 presented no sign of odontoblastic layer formation. Regarding calcification, none of the specimens in the study groups showed diffuse calcification. There was no pulp stone in groups 1 and 2 , but $20 \%$ of the specimens in groups 3 and 4 exhibited pulp stone (Figure 5; Table 3).

\section{Discussion}

The main purpose in vital pulp therapy is to activate the odontoblast-like cells to generate dentinal bridges and thus protect the underling soft tissue. ${ }^{1}$ The DPC technique

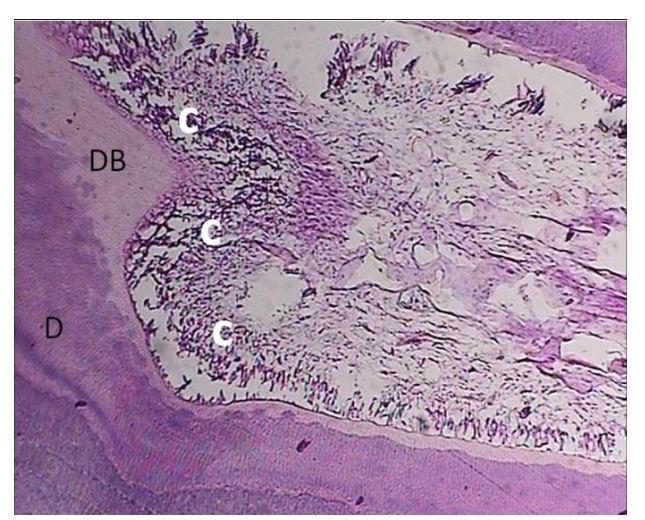

Figure 2. A Sample Treated With MTA+ LLRL (Group 2). Chronic inflammatory cells without any center of necrosis were seen. Abbreviations: MTA, mineral trioxide aggregate; LLRL, low level red laser; D, dentin; DB, dentinal bridge; C, chronic inflammation. 
Table 1. The Frequency (\%) of Inflammatory Reactions, Including Type, Intensity and Extension, in the Study Groups

\begin{tabular}{|c|c|c|c|c|c|c|}
\hline \multirow{2}{*}{ Inflammation } & \multirow{2}{*}{ Grade } & Group 1 & Group 2 & Group 3 & Group 4 & Group 5 \\
\hline & & No. $(\%)$ & No. (\%) & No. (\%) & No. (\%) & No. $(\%)$ \\
\hline \multirow{3}{*}{ Type } & I & $0(0)$ & $0(0)$ & $0(0)$ & $0(0)$ & $1(20)$ \\
\hline & II & $1(20)$ & $1(20)$ & $0(0)$ & $3(60)$ & $2(40)$ \\
\hline & III & $4(80)$ & $4(80)$ & $5(100)$ & $2(40)$ & $2(40)$ \\
\hline \multirow{3}{*}{ Intensity } & I & $0(0)$ & $0(0)$ & $0(0)$ & $0(0)$ & $0(0)$ \\
\hline & II & $1(20)$ & $1(20)$ & $0(0)$ & $3(60)$ & $3(60)$ \\
\hline & III & $4(80)$ & $4(80)$ & $5(100)$ & $2(40)$ & $2(40)$ \\
\hline \multirow{3}{*}{ Extension } & I & $0(0)$ & $0(0)$ & $0(0)$ & $0(0)$ & $0(0)$ \\
\hline & II & $1(20)$ & $1(6.2)$ & $0(0)$ & $3(60)$ & $3(60)$ \\
\hline & III & $4(80)$ & $4(93.8)$ & $5(100)$ & $2(40)$ & $2(40)$ \\
\hline
\end{tabular}

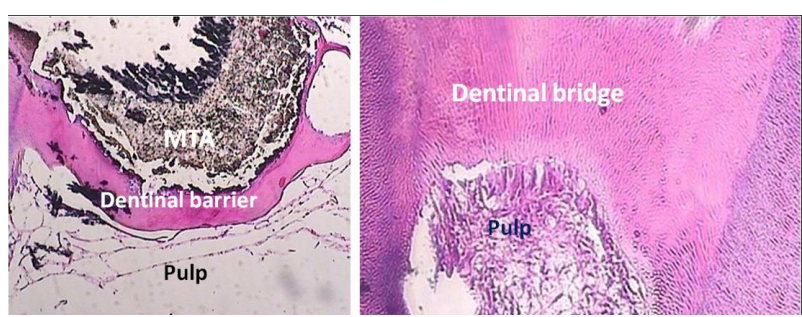

Figure 3. A Sample Treated With MTA (Group 1). A continuous dentinal bridge with regular tubules was formed at the pulpMTA interface ( $\times 40$ at the left side and $\times 100$ at the right side). Odontoblast-like cells and healthy pulp were seen. Abbreviation: MTA, mineral trioxide aggregate.

is an effort to maintain the vitality of dental pulp following exposure. In this method, the volume of the remaining dental pulp is greater than that of the other vital pulp therapy modalities. This greater amount of dental pulp tissue could be helpful in dentinal bridge formation. ${ }^{16}$ The dental pulp response to DPC technique has been investigated in previous studies using various pulp-capping materials. ${ }^{17}$ This study investigated the healing effect of low power laser therapy with or without MTA on exposed pulp tissue. This animal study was designed on histologic results, rather than on long- term clinical findings. The follow-up period was 8 weeks similar to most of the previous investigations, ${ }^{2,18,19}$ although some authors evaluated the pulpal effects of capping materials up to 150 days. ${ }^{15}$ Fibroblasts are the most frequent cells in the pulp and have a key role in the wound healing process. ${ }^{1}$ Previous studies demonstrated that low power laser therapy could increase the production of fibroblast growth factor (FGF)

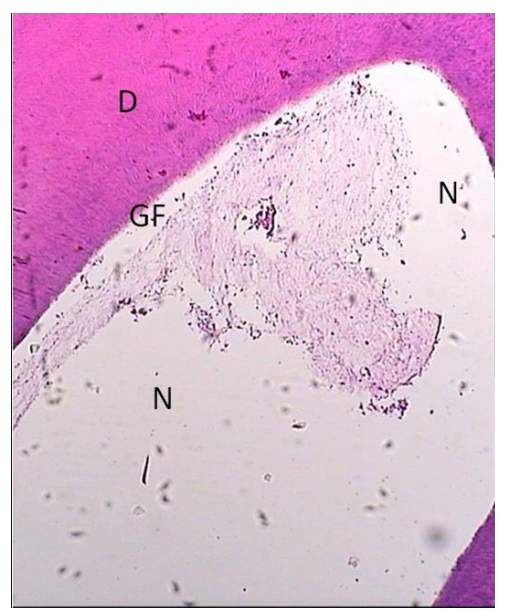

Figure 4. A Sample Treated With Gold Foil + LLRL (Group 4) Zone of necrosis was observed under the material. Also the dentinal bridge was not formed. Abbreviations: LLRL, low level red laser; D, dentin, GF, gold foil; $\mathrm{N}$ necrosis.

and reduce the formation of inflammatory mediators, and thus result in the promotion of remodeling and acceleration of wound healing process. ${ }^{20-23}$ However, under the conditions used in this study, LLLT had no additional benefit over MTA for improving the healing process in teeth underwent DPC treatment. This may be related to the excellent properties of MTA as a pulp capping material including perfect seal, high biocompatibility, stimulation of dentinal bridge formation, and stability in liquids. Furthermore, MTA indicates decontaminative, biostimulative, and hemostatic effects ${ }^{1}$ and these properties, altogether, could lead to a successful DPC treatment.

Table 2. The Frequency (\%) of Hard Tissue Formation Including Continuity, Morphology and Thickness in the Study Groups

\begin{tabular}{|c|c|c|c|c|c|c|}
\hline \multirow{2}{*}{ Dentinal Bridge } & \multirow{2}{*}{ Grade } & Group 1 & Group 2 & Group 3 & Group 4 & Group 5 \\
\hline & & No. $(\%)$ & No. (\%) & No. $(\%)$ & No. $(\%)$ & No. $(\%)$ \\
\hline \multirow{3}{*}{ Continuity } & I & $0(0)$ & $0(0)$ & $0(0)$ & $1(20)$ & $1(20)$ \\
\hline & II & $1(20)$ & $0(0)$ & $1(20)$ & $4(80)$ & $3(60)$ \\
\hline & III & $4(80)$ & $5(100)$ & $4(80)$ & $0(0)$ & $1(20)$ \\
\hline \multirow{3}{*}{ Morphology } & 1 & $0(0)$ & $0(0)$ & $0(0)$ & $1(20)$ & $1(20)$ \\
\hline & II & $4(80)$ & $5(100)$ & $4(80)$ & $3(60)$ & $3(60)$ \\
\hline & III & $1(20)$ & $0(0)$ & $1(20)$ & $1(20)$ & $1(20)$ \\
\hline \multirow{3}{*}{ Thickness } & I & $1(20)$ & $0(0)$ & $0(0)$ & $2(40)$ & $2(40)$ \\
\hline & II & $2(40)$ & $2(40)$ & $2(40)$ & $2(40)$ & $2(40)$ \\
\hline & III & $2(40)$ & $3(60)$ & $3(60)$ & $1(20)$ & $1(20)$ \\
\hline
\end{tabular}



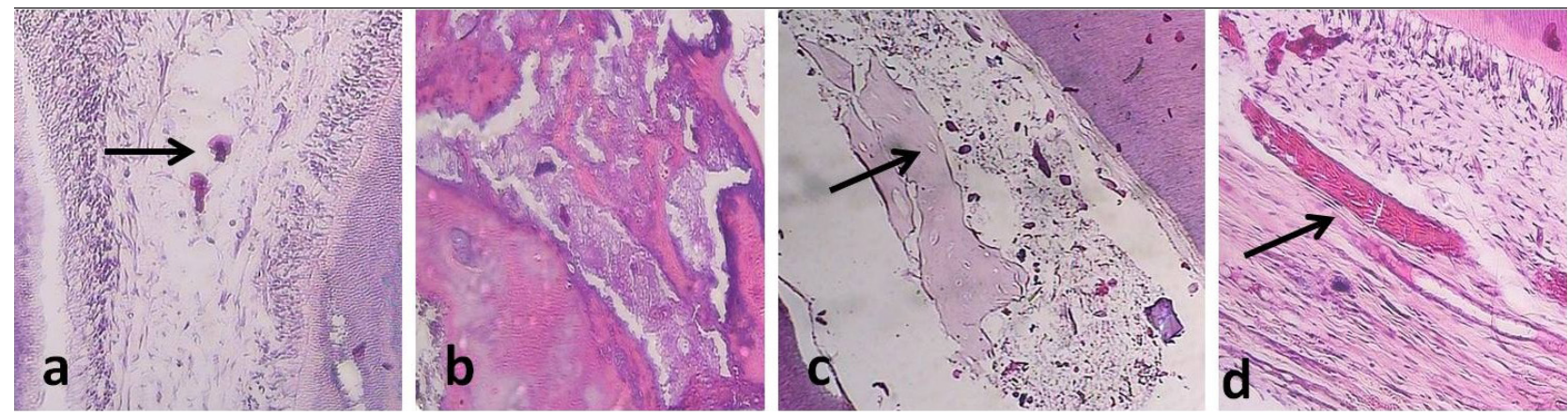

Figure 5. A Sample Treated With MTA+ LLIL (Group 3). Calcified basophilic nodules were seen in the pulp. (a) A sample treated with MTA+ LLRL (group 2). The calcified mass was seen in the pulp $(\times 100)$. (b) A sample treated with MTA+ LLIL (group 3). Calcified basophilic nodules and osteodentin tissue with lacuna containing cells were seen in the pulp. (c) A sample treated with MTA (group 1). Calcification along the collagen fibers was seen. (d) A sample treated with MTA (group 1). Calcification along the collagen fibers was seen. Abbreviations: MTA, mineral trioxide aggregate; LLRL, low level red laser; LLIL, low level infrared laser.

Table 3. The Frequency (\%) of Histopathological Changes in Soft Tissue Including Necrosis, Odontoblastic Layer Formation and Calcification in the Study Groups

\begin{tabular}{|c|c|c|c|c|c|c|}
\hline \multirow{2}{*}{ Soft Tissue Changes } & \multirow{2}{*}{ Grade } & Group 1 & Group 2 & Group 3 & Group 4 & Group 5 \\
\hline & & No. $(\%)$ & No. $(\%)$ & No. $(\%)$ & No. $(\%)$ & No. $(\%)$ \\
\hline \multirow{3}{*}{ Necrosis } & I & $0(0)$ & $0(0)$ & $0(0)$ & $0(0)$ & $0(0)$ \\
\hline & II & $0(0)$ & $0(0)$ & $0(0)$ & $1(20)$ & $1(20)$ \\
\hline & III & $5(100)$ & $5(100)$ & $5(100)$ & $4(80)$ & $4(80)$ \\
\hline \multirow{3}{*}{$\begin{array}{l}\text { Odontoblastic layer } \\
\text { formation }\end{array}$} & 1 & $0(0)$ & $0(0)$ & $0(0)$ & $1(20)$ & $1(20)$ \\
\hline & II & $3(60)$ & $2(40)$ & $3(60)$ & $3(60)$ & $4(80)$ \\
\hline & III & $2(40)$ & $3(60)$ & $2(40)$ & $1(20)$ & $0(0)$ \\
\hline \multirow{3}{*}{ Calcification } & 1 & $0(0)$ & $0(0)$ & $0(0)$ & $0(0)$ & $0(0)$ \\
\hline & $\|$ & $0(0)$ & $0(0)$ & $1(20)$ & $1(20)$ & $0(0)$ \\
\hline & III & $5(100)$ & $5(100)$ & $4(80)$ & $4(80)$ & $5(100)$ \\
\hline
\end{tabular}

In the present study, the occurrence of pulp inflammation was greater in groups 4 and 5 where laser therapy was used in association with gold foil instead of MTA. Sixty percent of the specimens in groups 4 and 5 showed inflammation, generally observed under the exposure site and not over the entire coronal pulp. There was no inflammation when LLIL was used in combination with MTA (group 3), whereas $20 \%$ of the specimens in LLRL + MTA (group 2) and MTA alone (group 1) groups experienced the occurrence of inflammation. The continuity and morphology of the dentinal bridge could be considered as a sign of successful pulp healing. ${ }^{1}$ Dentinal bridge formation was observed in $100 \%$ of the specimens in groups 1 to 3 and $80 \%$ of the specimens in groups 4 and 5 . However, in groups 1 to 3, complete bridge formation was observed in most of the specimens, whereas in groups 4 and 5, moderate contact of the capping material with the dental pulp was more frequent. The thickness of the dentinal bridge was also greater in MTA-treated (1 to 3 ) than gold foil-treated (4 and 5) groups. Twenty percent of the specimens in groups 4 and 5 showed atubular structure, whereas atubular dentin was not observed in any of the specimens in groups 1 to 3 . Regarding histopathological changes in soft tissues, no pulpal necrosis was observed in MTA-capped groups (1 to 3), whereas $20 \%$ of the specimens in gold foil-capped groups (4 and 5) demonstrated partial necrosis. The formation of odontoblastic layer oc- curred in all of the specimens in MTA-treated groups, and $80 \%$ of the specimens in groups 4 and 5 . Altogether, the findings of this study indicate that laser therapy could not be considered as an effective modality for treatment of exposed pulp tissue. The most influencing factor in pulpal response was the use of MTA against gold foil, and additional laser therapy did not enhance the healing process in teeth that underwent DPC treatment.

The reason why gold foil was used in groups 4 and 5 of this study was to determine the net effect of laser therapy on stimulating dentinal bridge formation and reducing inflammation in exposed pulp tissue, as the gold foil is an inert material. The specimens in groups 4 and 5, however, showed greater frequency of inflammation, necrosis and absence of odontoblastic layer formation compared to that observed in groups 1 to 3 where MTA was used instead of gold foil. It should be noted that gold foil does not have hemostatic and decontaminative properties of MTA, and provides less seal and marginal adaptation compared to MTA. Therefore, the poor results observed in groups 4 and 5 of this study could be attributed to improper marginal seal of gold foil that possibly neutralizes or decreases any healing effect of laser therapy on exposed pulp tissue. The results of this study indicated that low level laser irradiation on exposure site could not compensate the limitation of gold foil as a pulp capping material.

Most of the previous studies on the use of laser therapy 
in DPC employed high power lasers such as $\mathrm{CO}_{2}$ and diode, ${ }^{24-29}$ which have different mechanisms of action from low power lasers and so the results of those studies could not be compared with the present investigation. Regarding the effect of LLLT on DPC, Utsunomiya ${ }^{14}$ reported that the use of a gallium-aluminum-arsenide diode laser $(300 \mathrm{~mW})$ on exposed surface of the pulp resulted in earlier expression of lectins and collagens in laser irradiation group than in the control group, and thus they concluded that laser therapy lead to the acceleration of wound healing process in the pulp. In contrast, Ferriello et $\mathrm{al}^{20}$ evaluated the effect of a low level diode laser (wavelength 680 $\mathrm{nm}$; fluence $4 \mathrm{~J} / \mathrm{cm}^{2}, 60 \mathrm{~s}$ ) and different pulp-capping substances on proliferation of L-929 fibroblasts. They reported that LLLT did not improve the performance of dental pulp-capping materials and showed no effect on proliferation of L929 cells. Instead of DPC, some studies evaluated the effect of LLLT on pulpotomy of primary teeth. Golpayegani et $\mathrm{al}^{30}$ compared the effectiveness of LLLT with a semiconductor diode laser (wavelength $632 \mathrm{~nm}$, $151 \mathrm{~s}, 4.0 \mathrm{~J} / \mathrm{cm}^{2}$ ) with that of conventional formocresol in healing of the remaining pulp following pulpotomy of primary teeth. The clinical and radiographic success rate with LLLT (100\% and 89\%, respectively) was comparable to that of formocresol technique $(100 \%$ and $100 \%$, respectively), suggesting that LLLT can be used successfully as a complementary step to pulpotomy procedure. Marques et $\mathrm{al}^{13}$ evaluated the effect of LLLT (wavelength $660 \mathrm{~nm}$, $10 \mathrm{~mW}, 2.5 \mathrm{~J} / \mathrm{cm}^{2}, 10 \mathrm{~s}$ ) on pulpal response of primary teeth after pulpotomy. They found that the lowest degree of pulpal inflammation was present in LLLT $+\mathrm{Ca}(\mathrm{OH}) 2$ group and thus recommended laser therapy prior to the use of $\mathrm{Ca}(\mathrm{OH}) 2$ in order to provide satisfactory results regarding pulp tissue healing. On the other hand, De Coster et $\mathrm{al}^{11}$ in a systematic review concluded that the results of the LLLT plus either $\mathrm{Ca}(\mathrm{OH}) 2$ or $\mathrm{ZOE}$ application must be cautiously interpreted. The benefits achieved by these interactions are still unclear due to the lack of supportive studies. Pulpal reactions depend on the status of the tissue, the systemic condition of the patient, and some characteristics of capping materials, such as mechanism of action, $\mathrm{pH}$, antibacterial activity, and toxicity level. Improper restorations, lack of sealing which enables bacterial leakage and pulp inflammation, and even the irritating effect of the pulp capping materials can influence the results.

The energy density employed in this study was $7.5 \mathrm{~J} / \mathrm{cm}^{2}$ when using $630 \mathrm{~nm}$ wavelength and $6.25 \mathrm{~J} / \mathrm{cm}^{2}$ when using $810 \mathrm{~nm}$ laser. These energy densities were within the therapeutic window (between 0.01 and $10 \mathrm{~J} / \mathrm{cm}^{2}$ ) where biostimulatory effects of low power lasers are presented, whereas the inhibitory effects on physiologic activity can occur at higher dosages (greater than $12 \mathrm{~J} / \mathrm{cm}^{2}$ ). ${ }^{31,32}$ The results of a meta-analysis study indicate that the use of $632 \mathrm{~nm}$ wavelength and energy density in the range of 0.5 to $4.0 \mathrm{~J} / \mathrm{cm}^{2}$ provided the most effective outcomes in cellular proliferation and thus caused a significant improvement in tissue repair. ${ }^{33}$ Generally, contact mode is recommended for almost all laser applications with one exception: treating an open wound requires a 2 to $4 \mathrm{~mm}$ distance between the laser and the target tissue, providing a condition called non-contact mode. ${ }^{31}$ In this study, the non-contact mode was employed for laser irradiation on pulp wounds.

The limitation of this study was the single application of LLLT on teeth under DPC treatment. However, the exposed teeth should be restored immediately after pulp capping and it was difficult, if not impossible, to continue LLLT on restored teeth of dogs on the following days. Matic et $\mathrm{al}^{34}$ and Ezzati et $\mathrm{a}^{35}$ reported that intermittent laser irradiation had excellent effects on healing of skin ulcers in humans. In another study, Neiburger ${ }^{36}$ showed acceleration in healing of gingival ulcers following intermittent laser irradiation. Further studies are warranted to investigate the effect of intermittent application of LLLT following DPC using a larger sample size and long-term follow ups in the clinical situation.

\section{Conclusion}

Under the conditions used in this study, the type of pulp capping material was a more important factor than low power laser therapy in the success of DPC treatment. The use of MTA either alone or in combination with low power red and infra red lasers provided successful results in teeth that underwent DPC treatment.

\section{Ethical Considerations}

This study have been approved by ethical committee of Mashhad University of Medical Science, Mashhad, Iran.

\section{Conflict of Interests}

The authors deny any conflicts of interest related to this study.

\section{Acknowledgments}

The authors would like to thank the vice chancellor for research of Mashhad University of Medical Sciences for the financial support of this project (grant No. 88367). The results presented in this paper have been taken from a postgraduate student thesis (No. 441).

\section{References}

1. Ravindra SV, Mamatha GP, Sunita JD, Balappanavar AY, Sardana V. Morphometric analysis of pulp size in maxillary permanent central incisors correlated with age: An indirect digital study. J Forensic Dent Sci. 2015;7(3):208-214. doi:10.4103/0975-1475.172438.

2. Nowicka A, Wilk G, Lipski M, Kołecki J, BuczkowskaRadlińska J. Tomographic evaluation of reparative dentin formation after direct pulp capping with $\mathrm{Ca}(\mathrm{OH})$ 2, MTA, biodentine, and dentin bonding system in human teeth. J Endod. 2015;41(8):1234-1240. doi:10.1016/j. joen.2015.03.017.

3. Small B, Johnson W. Gold foil and its use in modern dentistry. Dent Today. 2006;25(3):92-96.

4. Tabarsi B, Parirokh M, Eghbal M, Haghdoost AA, Torabzadeh H, Asgary S. A comparative study of dental pulp response to several pulpotomy agents. Int Endod J. 2010;43(7):565-571. doi:10.1111/j.1365-2591.2010.01711.x.

5. Ahrari F, Madani AS, Ghafouri ZS, Tuner J. The efficacy of low-level laser therapy for the treatment of myogenous 
temporomandibular joint disorder. Lasers Med Sci. 2014;29(2):551-557. doi:10.1007/s10103-012-1253-6.

6. Ferreira AN, Silveira L Jr, Genovese WJ, et al. Effect of GaAIAs laser on reactional dentinogenesis induction in human teeth. Photomed Laser Ther. 2006;24(3):358-365. doi:10.1089/pho.2006.24.358.

7. Eshghpour M, Ahrari F, Najjarkar NT, Khajavi MA. Comparison of the effect of low level laser therapy with alvogyl on the management of alveolar osteitis. Med Oral Patol Oral Cir Bucal. 2015;20(3):e386-e392. doi:10.4317/ medoral.20375.

8. Moosavi H, Maleknejad F, Sharifi M, Ahrari F. A randomized clinical trial of the effect of low-level laser therapy before composite placement on postoperative sensitivity in class V restorations. Lasers Med Sci. 2015;30(4):1245-1249. doi:10.1007/s10103-014-1565-9.

9. Heravi F, Ahrari F, Mahdavi M, Basafa S. Comparative evaluation of the effect of Er:YAG laser and low level laser irradiation combined with CPP-ACPF cream on treatment of enamel caries. J Clin Exp Dent. 2014;6(2):e121-e126. doi:10.4317/jced.51309.

10. Heravi F, Moradi A, Ahrari F. The effect of low level laser therapy on the rate of tooth movement and pain perception during canine retraction. Oral Health Dent Manag. 2014;13(2):183-188.

11. De Coster P, Rajasekharan S, Martens L. Laser-assisted pulpotomy in primary teeth: a systematic review. Int $J$ Paediatr Dent. 2013;23(6):389-399.

12. Fernandes AP, Lourenço Neto N, Teixeira Marques NC, et al. Clinical and radiographic outcomes of the use of LowLevel Laser Therapy in vital pulp of primary teeth. Int J Paediatr Dent. 2015;25(2):144-150.

13. Marques NC Neto NL, de Oliveira Rodini C, et al. Lowlevel laser therapy as an alternative for pulpotomy in human primary teeth. Lasers Med Sci. 2015;30(7):1815-1822. doi:10.1007/s10103-014-1656-7.

14. Utsunomiya T. A histopathological study of the effects of low-power laser irradiation on wound healing of exposed dental pulp tissues in dogs, with special reference to lectins and collagens. J Endod. 1998;24(3):187-193. doi:10.1016/ s0099-2399(98)80181-7.

15. Asgary S, Eghbal MJ, Parirokh M, Ghanavati F, Rahimi H. A comparative study of histologic response to different pulp capping materials and a novel endodontic cement. Oral Surg Oral Med Oral Pathol Oral Radiol Endod. 2008;106(4):609614. doi:10.1016/j.tripleo.2008.06.006.

16. Witherspoon DE. Vital pulp therapy with new materials: new directions and treatment perspectives-permanent teeth. $J$ Endod. 2008;34(7):S25-S28. doi:10.1016/j.joen.2008.02.030.

17. Briso ALF, Rahal V, Mestrener SR, Dezan Junior E. Biological response of pulps submitted to different capping materials. Braz Oral Res. 2006;20(3):219-225. doi:10.1590/ s1806-83242006000300007.

18. Mestrener SR, Holland R, Dezan E. Influence of age on the behavior of dental pulp of dog teeth after capping with an adhesive system or calcium hydroxide. Dent Traumatol. 2003;19(5):255-261. doi:10.1034/j.1600-9657.2003.00167.x.

19. Lu Y, Liu T, Li X, Li H, Pi G. Histologic evaluation of direct pulp capping with a self-etching adhesive and calcium hydroxide in beagles. Oral Sur Oral Med Oral Pathol Oral Radiol Endod. 2006;102(4):e78-e84. doi:10.1016/j. tripleo.2006.02.020.
20. Ferriello V, Faria MR, Cavalcanti BN. The effects of lowlevel diode laser treatment and dental pulp-capping materials on the proliferation of L-929 fibroblasts. J Oral Sci. 2010;52(1):33-38. doi:10.2334/josnusd.52.33.

21. Yasukawa A, HRUI H, Koyama Y, Nagai M, Takakuda K. The effect of low reactive-level laser therapy (LLLT) with helium-neon laser on operative wound healing in a rat model. J Vet Med Sci. 2007;69(8):799-806. doi:10.1292/ jvms.69.799.

22. Maiya GA, Kumar P, Rao L. Effect of low intensity heliumneon $(\mathrm{He}-\mathrm{Ne})$ laser irradiation on diabetic wound healing dynamics. Photomed Laser Ther. 2005;23(2):187-90. doi:10.1089/pho.2005.23.187.

23. Madani AS, Ahrari F, Nasiri F, Abtahi M, Tuner J. Low-level laser therapy for management of TMJ osteoarthritis. Cranio. 2014;32(1):38-44. doi:10.1179/0886963413z.0000000004.

24. Suzuki M, Ogisu T, Kato C, Shinkai K, Katoh Y. Effect of $\mathrm{CO} 2$ laser irradiation on wound healing of exposed rat pulp. Odontology. 2011;99(1):34-44. doi:10.1007/s10266010-0140-5.

25. Suzuki M, Katsumi A, Watanabe R, Shirono M, Katoh Y. Effects of an experimentally developed adhesive resin system and $\mathrm{CO} 2$ laser irradiation on direct pulp capping. Oper Dent. 2005;30(6):702-718.

26. Moritz A, Schoop U, Goharkhay K, Sperr W. Advantages of a pulsed CO2 laser in direct pulp capping: a long-term. Lasers Surg Med. 1998;22:288-293.

27. Nammour S, Tielemans M, Heysselaer D, Pilipili Ch, De Moor R, Nyssen-Behets C. Comparative study on dogs between $\mathrm{CO}_{2}$ laser and conventional technique in direct pulp capping. Rev Belge Med Dent. 2008;64(2):81-86.

28. Olivi G, Genovese M, Maturo P, Docimo R. Pulp capping: advantages of using laser technology. Eur J Paediatr Dent. 2007;8(2):89-95.

29. Yazdanfar I, Gutknecht N, Franzen R. Effects of diode laser on direct pulp capping treatment. Lasers Med Sci. 2015;30(4):1237-1243.

30. Golpayegani MV, Ansari G, Tadayon N, Shams S, Mir M. Low-level laser therapy for pulpotomy treatment of primary molars. J Dent Tehran Univ Med Sci. 2009;6(4):168-174.

31. AlGhamdi KM, Kumar A, Moussa NA. Low-level laser therapy: a useful technique for enhancing the proliferation of various cultured cells. Lasers Med Sci. 2012;27(1):237249. doi:10.1007/s10103-011-0885-2.

32. Jahanbin A, Ramazanzadeh B, Ahrari F, Forouzanfar A, Beidokhti M. Effectiveness of Er:YAG laser-aided fiberotomy and low-level laser therapy in alleviating relapse of rotated incisors. Am J Orthod Dentofacial Orthop. 2014;146(5):565-572. doi:10.1016/j.ajodo.2014.07.006.

33. Nadin G, Goel BR, Yeung CA, Glenny AM. Pulp treatment for extensive decay in primary teeth. Cochrane Database Syst Rev. 2003(1):CD003220. doi:10.1002/14651858.cd003220.

34. Matić M, Lazetić B, Poljacki M, Duran V, Ivkov-Simić M. Low level laser irradiation and its effect on repair processes in the skin. Med Pregl. 2002;56(3-4):137-141. doi:10.2298/ mpns $0304137 \mathrm{~m}$.

35. Ezzati A, Bayat M, Khoshvaghti A. Low-level laser therapy with a pulsed infrared laser accelerates second-degree burn healing in rat: a clinical and microbiologic study. Photomed Laser Surg. 2010;28(5):603-611. doi:10.1089/pho.2009.2544.

36. Neiburger E. Rapid healing of gingival incisions by the helium-neon diode laser. J Mass Dent Soc. 1998;48(1):8-13. 